\title{
Integrating Diffusion of Innovations and Theory of Reasoned Action models to predict utilization of information technology by end-users
}

\author{
G. C. Moore \\ TRANSALTA Corporation \\ Calgary, Alberta, Canada \\ phone: (403) 267-4959 \\ fax: (403) 267-3630 \\ E-mail: moore.gary.c@transalta.ab.ca
}

\author{
I. Benbasat \\ University of British Columbia \\ Faculty of Commerce and Business Administration \\ Vancouver, BC, Canada V6T $1 Z 2$ \\ phone: (604) 822-8396 \\ fax: (604) 822-9574 \\ E-mail: izak@unixg.ubc.ca
}

\begin{abstract}
This paper reports on a field study investigating the adoption of an information technology (IT) by end-users. First, based on theories and empirical findings from research into the Diffusion of Innovations and the Theory of Reasoned Action, a model was developed of the factors influencing individual level decisions to use IT. The model was then field tested in a survey of 540 individuals in seven organizations. Results show that the model received good support and that it can be used for understanding the utilization of IT. Both one's own attitude and the expectations of others influenced the degree to which one used IT after adoption. Consistent with results from diffusion research, the most significant perceptions that had an effect on degree of use were ease of use, relative advantage and compatibility.
\end{abstract}

Keywords

Information systems adoption, diffusion of innovations, theory of reasoned action 


\section{INTRODUCTION}

There has been increased interest in the information systems (IS) research literature recently on predicting and explaining the utilization of information technology (IT) by end-users (Hartwick and Barki, 1994). Most of these studies have been based on the Theory of Reasoned Action and its variants, such as the "technology acceptance model" (Davis, 1989) and the Theory of Planned Behavior (Ajzen, 1991; Mathieson, 1991).

This paper reports on a research study conducted to propose and test a model for understanding the different degrees of use of end-user IT by individuals. What distinguishes this work from previous ones is that it explicitly draws upon two distinct yet theoretically related bodies of research. The first is research into the diffusion of innovations (Rogers, 1983), which in general investigates individuals' reactions to new products or processes, and why some innovations diffuse and others do not. Our research was not intended to study the diffusion of IT per se (i.e., its rate of adoption over time), but rather the extent to which individuals use the technology. The second is research on the Theory of Reasoned Action (Fishbein and Ajzen, 1975) which is a general theory applicable to an array of behaviors, including the forces which influence the use of IT. Diffusion research applies to the behavior of accepting or rejecting an innovation. Thus, to the extent that personal use of IT can be considered as an innovation within the work place, certain concepts of diffusion research could be used to apply the Theory of Reasoned Action to IT utilization.

In this study the generic perceptions of adopting a product or service (as developed in diffusion research) are used to serve as the beliefs used in the Theory of Reasoned Action. Measures for these beliefs and other constructs in the model were created through a rigorous instrument development process. The final stage of the study tested the model in a field survey, which included 540 respondents from seven organizations in a variety of industries. These steps are described in the sections which follow.

\section{THEORETICAL BASIS OF THE RESEARCH}

\subsection{Theory of Reasoned Action}

Theory of Reasoned Action (TRA) specifies the relationships between beliefs, attitudes, and behaviors. TRA is based on the proposition that an individual's overt behavior (B) is determined by the individual's intention to perform that behavior (BI). BI in turn is a function of two factors, one's Attitude towards performing the behavior itself $\left(A_{B}\right)$ and one's Subjective Norm (SN):

$\mathrm{B} \cong \mathrm{BI}=\mathrm{w}_{1}\left(\mathrm{~A}_{\mathrm{B}}\right)+\mathrm{w}_{2}(\mathrm{SN})$.

where $\mathrm{w}_{1}$ and $\mathrm{w}_{2}$ are the relative weights given to each component by the individual.

Subjective Norm is a function of two components: i) the individual's normative beliefs (NB), which are beliefs one has about what each of one's "important others", or salient referents, expects one to do with respect to a particular behavior, and ii) the individual's "motivation to comply" (MC) with each of the perceived expectations of the salient referents: 
$\mathrm{SN}=\Sigma\left(\mathrm{NB}_{\mathrm{j}} \mathrm{MC}_{\mathrm{j}}\right)$

$\mathrm{NB}_{\mathrm{j}}=$ perceived expectation of the jth referent

$\mathrm{MC}_{\mathrm{j}}=$ motivation to comply with the jth referent

One's attitude towards a behavior, $\mathbf{A}_{\mathbf{B}}$, is a function of one's belief $\left(b_{\mathfrak{i}}\right)$ that performing the behavior will lead to certain outcomes, and a weighted evaluation $\left(\mathrm{e}_{\mathrm{i}}\right)$ of those outcomes:

$\mathrm{A}_{\mathrm{B}}=\Sigma\left(\mathrm{b}_{\mathrm{i}} \mathrm{e}_{\mathrm{i}}\right)$.

$b_{i}=$ the expectation of the ith outcome

$\mathrm{e}_{\mathrm{i}}=$ the evaluation of the ith outcome

To identify those beliefs which are the basis of attitude in each situation, Ajzen and Fishbein (1980) suggest simply asking respondents to list their beliefs about the behavior in question. It is assumed that beliefs will be listed in the order of relative salience and that only salient beliefs have an effect. Furthermore, because Ajzen and Fishbein (1980) argue that beliefs are unique to each specific situation, a new set of beliefs must be elicited for each new situation.

\subsection{Theory of Reasoned Action and IT studies}

Researchers studying the use of IT have recently taken different approaches to defining the beliefs which contribute to one's attitude towards using IT. Christensen (1987) and Pavri (1988) followed the method suggested by Ajzen and Fishbein (1980) to identify relevant beliefs. More recently, researchers attempted to identify more generic ways to define beliefs. For example, Davis (1989) introduced a variant of TRA, which he called a Technology Acceptance Model (TAM). Based on a review of the IS literature, he identified two general constructs, perceived ease of use and perceived usefulness of the system, as the beliefs hypothesized to determine attitude. In a subsequent study, Davis et al. (1989) compared TAM to a model based explicitly on TRA. The beliefs for the TRA model were first elicited from an initial set of respondents, with the seven most frequently mentioned being chosen for the full study. TAM and TRA models were then compared. The results showed that a "parsimonious" causal structure for predicting behavior could be identified based only on usefulness and ease of use, i.e., the two general beliefs used in TAM had more power than the beliefs identified in the elicitation procedure. This lends support to developing models based on more general perceptions.

In a further study, Mathieson (1991) compared the "Theory of Planned Behavior" (Ajzen, 1991), which is an extension of TRA, to TAM. Mathieson also used an elicitation procedure to identify salient beliefs. He found that both models predicted Behavioral Intention well, but that TAM was "easier to use" because of the use of a standard set of instruments, which eliminates the need to elicit beliefs for every new study or context.

These studies are marked steps forward in the study of attitude within the IT usage literature. However, there still exists considerable inconsistency in the various studies in how attitude is formulated, and especially in how the particular beliefs that contribute to its formulation are identified and explicated. We believe that a fairly consistent approach to defining attitude and perceptions should be undertaken, rather than being dependent on the contingencies of a particular study. Thus, IT researchers should focus on identifying and 
investigating a generic set of beliefs about using IT to make a more general and cumulative approach to the study of IT implementation possible. The next sections outline such an approach.

\subsection{Diffusion of Innovations Theory at the individual level of analysis}

IT implementation can be viewed as basically a process of change. For example, Ginzberg (1981) proposed the use of a diffusion of innovations model to study the implementation of IS. Lucas et al. (1990), as the foundations for their model of implementation, refer to attitude models, including TRA and diffusion models. Kwon and Zmud (1987) have also argued for marrying the two streams of research represented by implementation studies and diffusion studies. It is only in recent years that IS researchers have relied on diffusion theories for studying adoption and use at the individual level (e.g., Moore, 1987; Brancheau and Wetherbe, 1990).

This research undertakes such a study by using diffusion research to provide a basis for identifying a set of generic perceptions or beliefs which could affect one's attitude towards using IT. It then integrates these perceptions with several constructs from TRA to develop and test a model which helps explain individual use of end-user IT. According to diffusion research, there are a variety of factors that can be identified as affecting the formation of one's attitude and subjective norms, such as the communication network of an individual. However, these issues are outside the scope of this paper.

\section{THE CONCEPTUAL FRAMEWORK}

The components of the research model shown in Figure 1 are described below.

\subsection{Usage}

In terms of TRA, personal work station (PWS) usage is the behavior of interest and hence is the dependent variable in this study. A PWS is defined as a set of computerized hardware and software tools designed for personal use by an individual. The key aspect of a PWS is that it is interactive information technology operated directly by a user. For this study, we focus on two dimensions of usage. The first dimension, diversity of use (Thompson et al., 1991), is the degree to which one uses a previously adopted product or process in a different use domain. The second is intensity, which is the degree to which the product or process is actually put to use (Thompson et al., 1991).

\subsection{Attitude towards adopting}

According to TRA, one's actual usage of IT will be a function of one's attitude towards its use. In this study we focus on the cognitive aspects, or perceptions, that a person has towards performing a behavior. In diffusion theory, the perceptions which are hypothesized to have an effect on attitude have been cast as the perceived characteristics of innovations, and have been shown in a number of studies to be linked to adoption/rejection decisions. Tornatzky and Klein (1982) found that compatibility, relative advantage, and complexity were consistently associated with innovative behaviors. Rogers and Shoemaker (1971) had earlier 


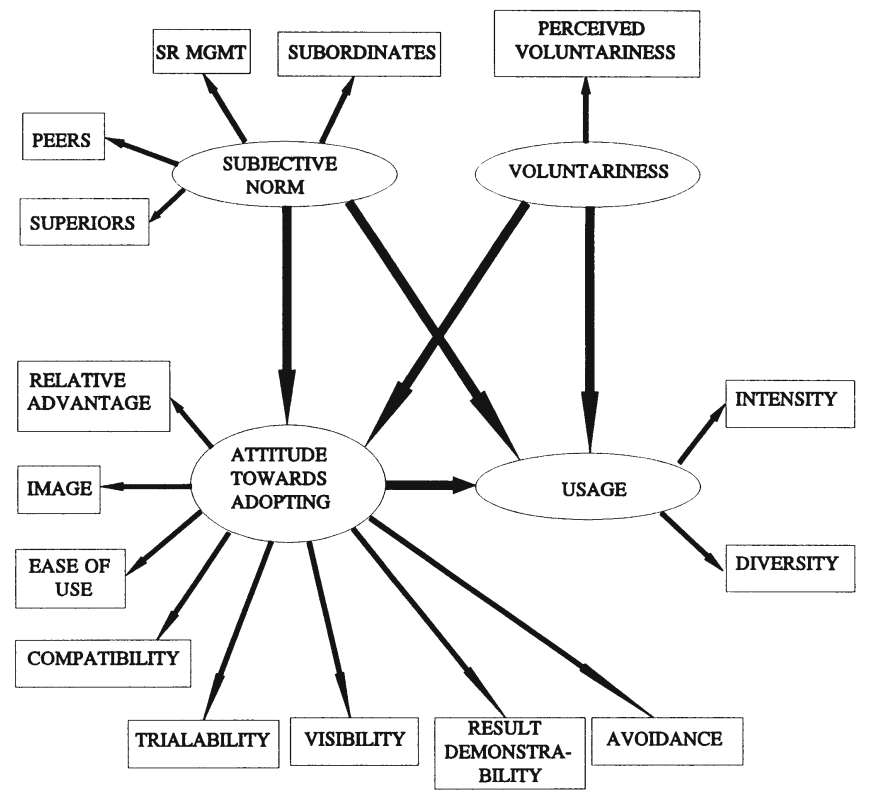

Figure 1 Research model.

identified these three characteristics, as well as trialability and observability. Because of the popularity of Rogers' work, which has become one of the most cited works in the social sciences, we decided to include these five in the current study. Finally, a sixth characteristic, image, was also included since Rogers had indicated that although image might be subsumed under relative advantage, in some instances it was a motivating factor on its own.

The next stage was to develop an instrument to measure these various characteristics (see Moore and Benbasat, 1991 for full details). In the instrument development process, observability was found to tap two different constructs, result demonstrability and visibility, and thus was split. As a result, seven perceived characteristics of using PWS were eventually included in the study, defined as follows:

- Relative Advantage: the degree to which using a PWS is perceived as being better than using its precursor.

- Compatibility: the degree to which using a PWS is perceived as being consistent with the existing values, and past experiences of the potential adopter.

- Ease of Use: the degree to which a PWS is perceived as being easy to use (Note: this term rather than "complexity" was used here to be congruent with the terminology in the IS literature).

- Trialability: the degree to which a PWS may be experimented with before adoption. 
- Image: the degree to which using a PWS is perceived to enhance one's image or status in one's social system.

- Result Demonstrability: the degree to which the results of using a PWS are observable and communicable to others.

- Visibility: the degree to which a PWS is apparent to the sense of sight.

In addition to the above, an eighth perception, Computer Avoidance, was investigated to specifically capture respondents' potential aversion or avoidance reactions to IT. Igbaria (1993) observed that "computer avoidance" influenced behavioral intent negatively. This perception includes management's potential use of IT to monitor workers' performance, IT's potentially negative impacts on one's health, and its potential "deskilling" aspects. It was concluded that these beliefs could potentially influence attitudes towards using IT.

\subsection{Subjective norm}

One of the potential determinants of behavior is the Subjective Norm (SN), as defined in TRA. SN is formed from one's motivation to comply with what one believes others expect one to do (termed the normative belief). Several individuals may serve as potential "referents" who might influence one's behavior with respect to PWS usage. These include one's co-workers and senior management. Within IS research, there is considerable evidence that several of these referents actually influence IT use, e.g., a popular nostrum for successful IS implementation has been "senior management support" and the presence of a "champion". The expectations of these various individuals that others should use the IT are all subsumed within the SN.

Although TRA does not postulate any interaction effects between $\mathrm{SN}$ and attitude, previous research has shown that these effects can exist (e.g., Ryan, 1982). Within IS, Christensen (1987) found that the components of SN had a direct effect on one's eventual behavior, as well as on one's attitude with respect to DSS adoption. Therefore, a link between subjective norm and attitude is included in the model.

\subsection{Perceived voluntariness of PWS usage}

Degree of voluntariness (V) of use explicitly addresses formal requirements in one's job to perform a behavior, whereas $\mathrm{SN}$ refers to the perceived social pressure to perform a certain behavior (Ajzen, 1991, p.188). SN sets an informal requirement; it is up to the individual to conform with the expectations of others or not. Voluntariness, however, refers to how an individual perceives formal job requirements. It refers to the power an individual has to perform, or not perform, a certain behavior.

The separate nature of $\mathrm{SN}$ and $\mathrm{V}$ is supported by the Theory of Planned Behavior (TPB) (Ajzen, 1991), proposed as an extension to TRA. According to Ajzen:

Behavioral Intention can find expression in behavior if the behavior in question is under volitional control, i.e., the person can decide at will to perform or not perform the behavior (p.182). 
Accordingly, Ajzen has added a new factor to the TPB named perceived behavioral control, in addition to attitudes and SN which are part of TRA. While Ajzen casts perceived behavioral control in terms of abilities, opportunities, and resources available to individuals to enable performance, we view Voluntariness as a factor that influences behavior in a similar fashion to perceived behavioral control. This is because Voluntariness, the perception of what an individual thinks he/she is required or not required to perform, and perceived behavioral control, which is described by Ajzen as "volitional control", appear to be closely related constructs. This similarity provides an a priori justification for the inclusion of SN and $\mathrm{V}$ as two separate, and distinct, factors in our model in the same way that the TPB includes both SN and perceived behavioral control. Furthermore, Hartwick and Barki (1994) observed major differences between voluntary and mandatory users and suggest that more work is needed on this topic.

\subsection{Behavior}

Behavioral intention, a component within TRA, is not included in the research design. If no other variables intervened once an attitude and subjective norm were formed, or if the behavior were to be performed immediately, then intention could be dropped from the model without a loss of information. Intentions are used to predict behavior, and therefore to be of value "it is important to measure [them] as close as possible to the behavioral observation" (Ajzen and Fishbein, 1980, p.47). Indeed, in this study we are not attempting to predict future behavior; rather, we are attempting to determine how current behavior is related to subjective norm and attitude.

\section{EMPIRICAL TEST}

\subsection{The study sample}

Data were gathered from both users and non-users of PWS in seven organizations. These firms, representing diverse industries, covered the range of private to public sector organizations. Firms participating also had made the PWS generally available to their employees. Terminals or personal computers were provided, and applications were accessible either locally on personal computers, or on the mainframe or through a local area network. The reason for choosing organizations which made the technology accessible was to make sure that individuals who wished to use the technology had access to it.

A total of 810 questionnaires were distributed, with 540 usable ones returned, for an average response rate of $67 \%$.

Basic demographic statistics were collected to assess how well the sample represented the population of employees within the firms. $60 \%$ of the respondents were males. $44 \%$ were in supervisory and management positions, $34 \%$ were professional and technical employees, and $18 \%$ clerical staff. Over $60 \%$ had post-secondary education. While no specific data are available, conversation with the company representatives indicated that the proportion of respondents in each category reflects the overall proportions in the organizations. 


\subsection{Measurement of constructs}

4.2.1 Perceived Characteristics of Using PWS. Prior to this study, an extensive construct and instrument development process was undertaken to create several scales to measure the perceived characteristics (described in Section 3.2), including several procedures to ensure the scales' validity and reliability, as described in Moore and Benbasat (1991). After the development process, a total 50 items were chosen to measure these eight perceived characteristics. They were listed in the survey instrument in a random order, i.e., not grouped by perceived characteristics. The items were based on seven point scales, ranging from strongly disagree to strongly agree. An example of an item (for relative advantage) is "Using a PWS improves my job performance".

The reliability statistics for the various scales, based on the data from 540 respondents who participated in the study, indicate all scales were above 0.70 , and most above 0.80 .

4.2.2 Subjective Norm. Items for subjective norm were developed following the recommendations of Ajzen and Fishbein (1980). They were based on seven point scales with "likely-unlikely" anchors. For the normative beliefs (NB) respondents were presented with statements such as "[Referent A] thinks I should use a PWS in my job". The various referents, determined through interviews with a sample of respondents, included subordinates, peers, supervisors, and senior management. For the motivation to comply (MC) the statements were phrased "generally speaking, I want to do what [Referent A] thinks I should do". Subjective Norms for each referent group were calculated by multiplying their respective NB's and MC's together.

4.2.3 Usage. Intensity was operationalized, similar to Thompson et al. (1991), as the number of hours an individual uses the PWS. Respondents were asked to indicate the average number of hours of usage per week for each PWS function. The total number of hours of use per week was then computed as the sum of these responses. A second item, physically separate from the first item, asked the general question of total hours of use as follows: "Overall, how many hours per week do you use a PWS?". A scale for intensity was then constructed from the two items, with a resulting reliability of 0.88 .

Diversity, which reflects the number of new task domains in which IT is used, was operationalized, similar to Thompson et al. (1991), as the number of different functions that an individual uses on the PWS. The functions chosen to reflect "breath" included: word processing, computer modelling, spreadsheets, graphics, information retrieval, database management, electronic mail, electronic calendars, report generation, and use of interactive programming languages and statistical analysis packages. In addition to these "generic" functions, some specific application areas such as geoscience, accounting, and human resources were included as options. Data on the number of different functions used were obtained from three sources. The first asked when the respondent first used each function. If a date was provided, this was taken as an indication that the specific function was being used. The second source was the number of hours of use per week of each function. A response greater than zero indicated use of that function. A third item asked whether each function, if used, was used on a mainframe or microcomputer. The reliability of the threeitem scale was 0.98 . 


\section{FINDINGS OF THE STUDY}

\subsection{Adopters vs. non-adopters}

Table 1 provides comparative statistics for adopters and non-adopters. As can be seen, while the various perceptions of using PWS are generally positive, there are statistically significant differences between adopters' and non-adopters' perceptions for every characteristic except computer avoidance.

Table 1 Comparison of responses: adopters versus non-adopters

I. Proportion of Users Versus Non-Users In Sample

\begin{tabular}{|c|c|c|c|c|c|c|}
\hline \multirow[b]{2}{*}{ Organizational Level } & \multicolumn{2}{|c|}{ Adopters } & \multicolumn{2}{|c|}{ Non-Adopters } & \multicolumn{2}{|c|}{ Total } \\
\hline & $\#$ & $\begin{array}{c}\% \text { of } \\
\text { level }\end{array}$ & \# & $\begin{array}{l}\% \text { of } \\
\text { level }\end{array}$ & \# & $\begin{array}{l}\% \text { of } \\
\text { Sample }\end{array}$ \\
\hline $\begin{array}{l}\text { Executive } \\
\text { Middle Management } \\
\text { Supervisory } \\
\text { Professional } \\
\text { Technical } \\
\text { Clerical }\end{array}$ & $\begin{array}{r}9 \\
73 \\
101 \\
95 \\
45 \\
78 \\
\end{array}$ & $\begin{array}{l}69 \% \\
74 \% \\
78 \% \\
77 \% \\
76 \% \\
80 \%\end{array}$ & $\begin{array}{r}4 \\
25 \\
29 \\
29 \\
14 \\
20 \\
\end{array}$ & $\begin{array}{l}31 \% \\
26 \% \\
22 \% \\
23 \% \\
24 \% \\
20 \%\end{array}$ & $\begin{array}{r}13 \\
98 \\
130 \\
124 \\
59 \\
98 \\
\end{array}$ & $\begin{array}{r}3 \% \\
19 \% \\
25 \% \\
24 \% \\
11 \% \\
19 \%\end{array}$ \\
\hline $\begin{array}{l}\text { Total } \\
\text { Percent of Sample }\end{array}$ & 418 & $77 \%$ & 122 & $23 \%$ & 540 & $100 \%$ \\
\hline
\end{tabular}

II. Variable Means and Tests For Differences

\begin{tabular}{|c|c|c|c|c|}
\hline & Adopters & Non-Adopters & $\underline{\text { Z-Scores }}$ & Sign \\
\hline $\begin{array}{l}\text { Percelved Cnaracteristics } \\
\text { Image }\end{array}$ & 4.3 & 3.9 & -3.08 & .00 \\
\hline Relative Advantage & 5.9 & 4.8 & -9.39 & .00 \\
\hline Compatibility & 5.7 & 4.4 & -9.68 & .00 \\
\hline Ease of Use & 5.1 & 4.5 & -5.54 & .00 \\
\hline Result Demonstrability & 5.8 & 4.9 & -7.81 & .00 \\
\hline Trialability & 4.6 & 4.3 & -2.23 & .03 \\
\hline Visibility & 5.9 & 5.3 & -5.13 & .00 \\
\hline Computer Avoidance & 2.1 & 2.1 & -0.04 & .97 \\
\hline Voluntariness & 3.3 & 5.0 & -10.01 & .00 \\
\hline Subjective Norms & & & & \\
\hline Peers & 6.10 & .11 & -8.07 & .00 \\
\hline Supervisors & 9.39 & .08 & -9.06 & .00 \\
\hline Senior Management & 8.75 & -.16 & -9.06 & .00 \\
\hline Subordinates & 5.26 & -.53 & -7.78 & .00 \\
\hline
\end{tabular}

Significant differences between adopters and non-adopters also exist in the subjective norm for all referent groups. Non-adopters report neutral to slightly negative subjective norms, whereas adopters report significantly more positive norms. A negative subjective norm would 
indicate that the respondent thought that the relevant referent did not expect the respondent to use the PWS. For adopters, the strongest "pressure" to use the PWS comes from their immediate supervisors and senior management, with slightly less pressure from peers and subordinates.

\subsection{Results of model test}

The model in Figure 1 was tested using structural equation modelling as implemented in LISREL VI (Joreskog and Sorbom, 1984). In order to analyze the results with respect to the research model, the sample was first randomly split into two groups: Sample 1 and Sample 2. Sample 1 was used to initially assess and calibrate the model as necessary, and then Sample 2 was used to validate the results.

5.2.1 Model Fit. The fit of the model to the data was assessed by generally following the guidelines suggested by Bagozzi and Yi (1988). (For full details see Moore and Benbasat, 1993).

The squared multiple correlations and factor loadings for several indicators of attitude were problematic, including the following: image, result demonstrability, trialability, visibility, and computer avoidance. The loading of computer avoidance was not significant. The adjusted goodness of fit index (AGFI), which ranges from 0 to 1 , for the overall model was also rather low at .71 .

As a result of the analysis of the internal fit of the model, we decided to drop the problematic indicators for attitude. While some indicators were dropped, none of the causal paths in the initial model were altered, and hence the model's basic structure was not changed. The model was then run again, still using Sample 1, and the internal fit of the model was re-assessed. In this instance, all the criteria for goodness of internal fit were met.

Once these statistics were evaluated, the next step was to assess the overall fit of the model to the data. Wheaton et al. (1977) suggest that a chi-square five times greater than the degrees of freedom is acceptable, but the smaller the ratio the better. For the full model, however, chi-square/d.f. is approximately 5.3. Furthermore, AGFI, at .71, indicates a somewhat poor fit of the model to the data. Although there is no standard against which to judge these values, they can be used to compare the initial model against that which eliminated the problematic indicators for attitude. For this revised model, the $\chi^{2} / \mathrm{df}$ ratio improved to 3.5 , and the AGFI to .86 . This indicated that the revised model fit the data much better than the full model.

The next step was to cross-validate the model. This was necessary to ensure that the final model was not a case of simply fitting the model to the data. Up to this stage, the analysis had been conducted using only one half of the sample, i.e., Sample 1. Cross-validation is conducted by fitting the parameters estimated in the initial (calibration) sample (Sample 1) on a withheld (validation) sample (Sample 2) and assessing the goodness of fit indices. The validation exercise showed that all of the assessment indices are relatively good for the model indicating that the model has a fairly good fit to the data. It should be noted that although changes were made to the indicators for some constructs (primarily attitude), the fundamental nature of the model was not changed. Since no paths were added or deleted among the constructs in the original model, the test of the model was more one of confirmation than exploration. 
5.2.2 Assessment of Model. Figure 2 provides the parameter estimates for the model using the validation sample. All paths are statistically significant.

The standardized procedure provided by LISREL rescales only the latent variables (i.e., attitude, subjective norm, voluntariness, and usage) to have a variance of 1.0 , while leaving the observed measures, or indicators (e.g., relative advantage and ease of use), in their original scales. Each loading of an observed measure, therefore, should be interpreted as the amount of change in the original observed measure given a one standard deviation change in the corresponding latent variable it reflects. In practical terms, the loadings shown in Figure 2 indicate that compatibility has the highest influence on attitude, followed by relative advantage and ease of use. For subjective norm, the most influential indicators are superiors and senior management, while peers and subordinates have lesser influence. For usage, number of functions (diversity), as compared to number of hours (intensity), is the more influential indicator.

In terms of the relationships among the latent variables, attitude has a significant positive effect on usage (.52). Furthermore, attitude has the greatest direct effect of the three constructs affecting usage. Subjective norm has a significant effect on both usage (.18) and attitude (.55). Finally, voluntariness is also inversely related to both usage (-.40) and attitude $(-.16)$.

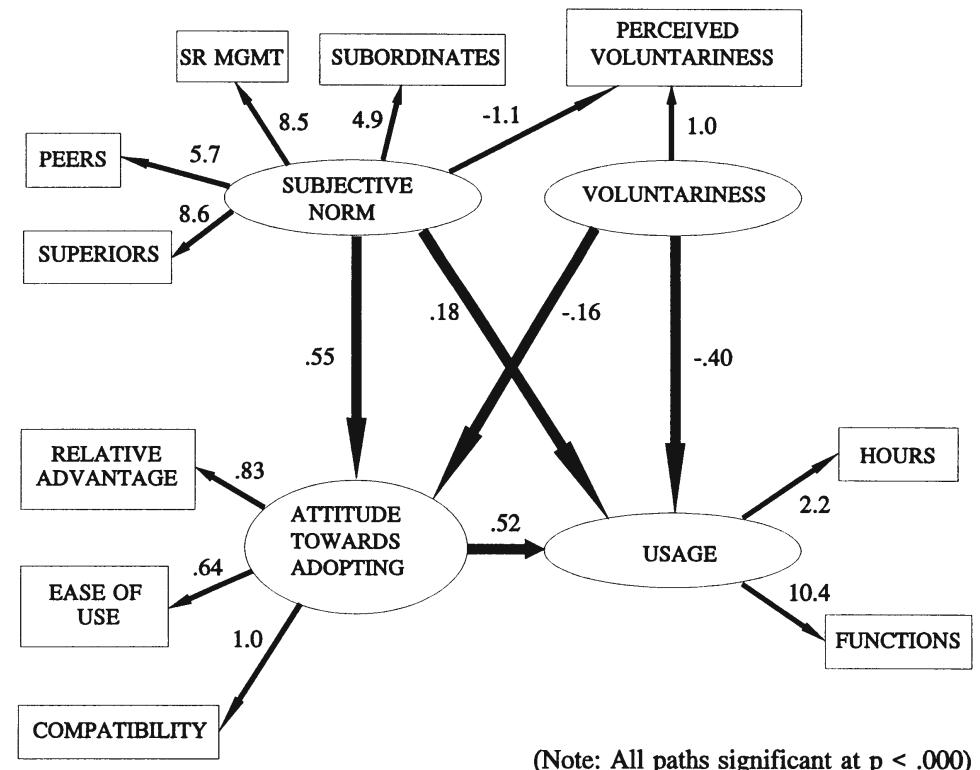

Figure 2 LISREL standardized solution. 
In addition to their direct effects on usage, both subjective norm and voluntariness have indirect effects through attitude. Their total effect can be calculated as the sum of their direct effect (the path coefficient to usage), and their indirect effect (the product of their path coefficient to attitude and that from attitude to usage). For subjective norm, that is:

\section{Total Effect of Subjective Norm on Usage $=.18+(.52 \times .55)=.47$}

The total effects (.47) of subjective norm on usage are close to the effect of attitude (.52). A result not predicted by theory, however, is the fact that its direct effect on usage (.18) is approximately only a third of its direct effect on attitude (.55). Nevertheless, this does parallel the findings of Christensen (1987) who found that the direct effect of subjective norm on one's intention to use a DSS was approximately $54 \%$ of its effect on attitude.

As with subjective norm, the total effects of voluntariness can be calculated as follows:

\section{Total Effect of Voluntariness on Usage $=-.40+(-.16 \times .52)=-.48$}

The above result shows that the total effects of voluntariness on usage $(-.48)$ is approximately equal to that of subjective norm, and slightly less than attitude. Nevertheless, its direct effect on usage (-.40) dominates, being approximately $2 \frac{1 / 2}{2}$ times greater than its effect on attitude (-.16).

In summary, these results provide support for the model. In addition, the squared multiple correlations (which are analogous to $\mathrm{R}^{2}$ ) for the structural equations indicate that a fair amount $(65 \%)$ of the variance in usage is accounted for by attitude, subjective norm, and voluntariness, i.e., a good model fit.

\section{LIMITATIONS}

This study is cross-sectional. Thus, although much of the analysis is described in causal terms, causality cannot be demonstrated because the study was not longitudinal. The model tested investigated the concurrent relationships between subjective norm, attitude and extent of IT use. Nevertheless, this research tested a model based on elements of theories proposed in TRA and diffusion of innovation literatures and supported by other empirical research. We believe that our approach is a logical extension of these work and that the variables and relationships tested were appropriate. For example, a recent study by Hartwick and Barki (1994) found support for the use of TRA in a similar context. Even though they operationalized attitudes differently by using a semantic differential scale (e.g., good/bad) to measure feelings concerning system use, i.e., unlike utilizing a set of beliefs generated from the diffusion of innovations literature as was done in this paper, their results and those in this paper are quite similar. Hartwick and Barki (1994) state that:

strong support was obtained for TRA, both longitudinally (using predevelopment attitude, subjective norm, and intention to predict post implementation system use) and cross-sectionally (using post implementation attitude, subjective norm and intention to predict contemporaneous system use). (p.458)

Furthermore, the direct contributions (effects) of subjective norm and attitudes to explaining usage in our study (see Figure 2) and to intentions to use in the Hartwick and 
Barki (1994) study are along the same direction, with attitude having a stronger direct effect on behavior than subjective norm in both studies. Similarly, Taylor and Todd (1995) report that the factors affecting behavioral intent, in order of the strength of their influence, were attitude, perceived behavioral control, and subjective norm. Our study also found the same level of impact on behavior, from highest to lowest, for the direct effects of attitude, voluntariness (corresponding to perceived behavioral control), and subjective norm. The close correspondence between this study and others provides additional assurance that the results of our study have validity in spite of its focus on concurrent behavior. In summary, the results of this study support the research model, or more conservatively, do not reject it. Nevertheless, longitudinal studies must certainly be undertaken to fully investigate the causal effects of the various factors and their relationships over time. An extension to TRA could indeed include the "feedback" loop to subjective norms and attitudes.

\section{CONTRIBUTIONS TO RESEARCH}

There is a lack of IS research which propose generic theories to deal with a variety of new IT. The primary goal of this research, therefore, was to develop a model for understanding the utilization of end-user IT in particular, and of systems implementation in general. To do this, the study borrowed and integrated concepts from TRA and diffusion of innovations research, and extended them explicitly into the study of IT implementation. It is believed that the results of this study support the model that was developed. This has several implications.

First, this study helps to establish a foundation for further research. By extending the proposed model beyond the study of the utilization of the PWS, it could help researchers understand and investigate other IT implementations, such as executive information systems and expert systems. Second, this study provides support for IS researchers to adopt and use constructs from TRA and diffusion of innovations research. It shows that, as postulated by TRA, both the subjective norm and attitude have significant effects on a potential adopter's behavior and provides support to previous findings that an interaction between these two factors can occur. With respect to diffusion research, this study has shown the link between the perceived characteristics of using PWS and behavior. In particular, the three perceptions which loaded on attitude in the final model, namely relative advantage, compatibility, and ease of use, were also found to be the ones most consistently associated with adoption (Tornatzky and Klein, 1982). This might suggest that such factors as trialability and result demonstrability become less important after one has adopted the technology. This issue certainly deserves further research.

In conclusion, this study has developed and tested a model to explain the degree of use of an IT after its initial adoption. We recommend that its power and applicability to other IT applications be investigated in order to assess the degree to which it could be generalized to all IT domains and the extent to which it could be used to provide prescriptions.

\section{ACKNOWLEDGEMENTS}

We would like to thank Dr. Wynne Chin, University of Calgary, for his valuable advice on LISREL modelling. This work was partially supported by funds provided by the Natural Sciences and Engineering Research Council of Canada. 


\section{REFERENCES}

Ajzen, I. (1991) The Theory of Planned Behavior. Organizational Performance and Human Decision Processes, 50, 79-211.

and Fishbein, M. (1980) Understanding Attitudes and Predicting Behavior. PrenticeHall Inc., Englewood Cliffs, NJ.

Bagozzi, R.P. and Yi, Y. (1988) On the Evaluation of Structural Equation Models. Journal of the Academy of Marketing Science, 16, 74-94.

Brancheau, J.C. and Wetherbe, J.C. (1990) The Adoption of Spreadsheet Software: Testing Innovation Diffusion Theory in the Context of End-User Computing. Information Systems Research, 1, 115-143.

Christensen, G.E. (1987) Successful Implementation of Decision Support Systems: An Empirical Investigation of Usage Intentions and Behavior. Unpublished Doctoral Dissertation, University of California at Los Angeles.

Davis, F.D. (1989) Perceived Usefulness, Perceived Ease of Use, and User Acceptance of Information Technology. MIS Quarterly, 13, 318-339.

, Bagozzi, R.P., Richard P. and Warshaw, P.R. (1989) User Acceptance of

Computer Technology. Management Science, 35, 982-1003.

Fishbein, M. and Ajzen, I. (1975) Belief, Attitude, Intention, and Behavior: An Introduction to Theory and Research. Addison-Wesley, Reading.

Ginzberg, M. (1981) Key Recurrent Issues in the MIS Implementation Process. MIS Quarterly, 5, 47-59.

Hartwick, J. and Barki, H. (1994) Explaining the Role of User Participation in Information Systems Use. Management Science, 40, 440-465.

Igbaria, M. (1993) User Acceptance of Microcomputer Technology: An Empirical Test. OMEGA, 21, 73-90.

Joreskog, K.G., and Sorbom, D. (1984) LISREL VI: Analysis of the Structural Relationships by Maximum Likelihood Instrumental Variables and Least Squares Methods. Scientific Software Inc., Moresville, Indiana.

Kwon, T.H. and Zmud, R.W. (1987) Unifying the Fragmented Models of Information Systems Implementation, in Critical Issues in Information Systems Research (eds. R.J. Boland and R.A. Hirscheim), Wiley and Sons, New York, 227-251.

Lucas, H., Ginzberg M.J. and Randall L.S. (1990) Information Systems Implementation: Testing a Structural Model. Ablex Publishing Co., Norwood, NJ.

Mathieson, K. (1991) Predicting User Intentions: Comparing the Technology Acceptance Model with the Theory of Planned Behavior. Information Systems Research, 2, 173-191.

Moore, G.C. (1987) End User Computing and Office Automation: A Diffusion of Innovations Perspective. Infor, 25, 214-235.

and Benbasat, I. (1991) Development of an Instrument to Measure the Perceived Characteristics of Adopting an Information Technology Innovation. Information Systems Research, 2, 192-222.

(1993) Empirical Examination of a Model of the Factors Affecting Utilization of Information Technology by End-Users. Working Paper, Faculty of Commerce, University of British Columbia.

Pavri, F. (1988) An Empirical Study of the Factors Contributing to Microcomputer Usage. Unpublished Doctoral Dissertation, University of Western Ontario.

Rogers, E.M. (1983) Diffusion of Innovations. Third Edition, The Free Press, New York. 
York.

and Shoemaker, F.F. (1971) Communication of Innovations. The Free Press, New

Ryan, M.J. (1982) Behavioral Intention Formation: The Interdependency of Attitudinal and Social Influence Variables. Journal of Consumer Research, 9, 268-277.

Taylor, S. and Todd, P. A. (1995) Understanding Information Technology Usage: A Test of Competing Models. Information Systems Research, 6, 144-176.

Thompson, R.L., Higgins, C.A., and Howell, J.M. (1991) Personal Computing: Toward a Conceptual Model of Utilization. MIS Quarterly, 15, 125-143.

Tornatzky, L.G., and Klein, K.J. (1982) Innovation Characteristics and Innovation Adoption Implementation: A Meta-Analysis of Findings. IEEE Transactions on Engineering Management, 29, 28-45.

Wheaton, B., Muthen, B., Alwin, D., and Summers, G. (1977) Assessing Reliability and Stability in Panel Models, in Sociological Methodology (ed. D. Heise), Jossey-Bass, San Francisco, 84-136.

\section{BIOGRAPHY}

Gary C. Moore is with the TRANSALTA Corporation, Calgary, Canada. He received his $\mathrm{Ph} . \mathrm{D}$. in Management Information Systems from the University of British Columbia in 1989. Prior to receiving his doctorate he had a number of years of experience as a practitioner and consultant in the information management field. His research interests include I/S strategy, managing end user computing, I/S-user relationships, and the diffusion of innovations, including the introduction of new information technologies.

Izak Benbasat is CANFOR Professor of Management Information Systems at the Faculty of Commerce and Business Administration, the University of British Columbia, Vancouver, Canada. He received his Ph.D. in Management Information Systems from the University of Minnesota in 1974. His research interests are in studying the adoption of new information technologies, evaluating alternative human-computer interfaces, measuring the effectiveness of decision support tools, and investigating the role of explanations in expert systems. He is a Co-Senior Editor of MIS Quarterly, and serves on the editorial boards of Information Systems Research, and Accounting, Management and Information Technologies. 